\title{
SUGARCANE WAX EXTRACTION: INFLUENCE OF SOME PROCESS PARAMETERS
}

\author{
Victoria H. R. da Costa, Vitoria R. S. da Silva, Aline O. Guizelini, Patricia. F. M. Martinez
}

\begin{abstract}
Traditionally, sugarcane wax has been obtained from rotative filter cake produced during sugar and alcohol production. However, another waste that could be used as wax source is the peel that comes from sugarcane juice production (garapa). This material should also present a considerable amount of wax, since plants produce waxes into and on its surfaces as a way to control evaporation, wettability and hydration.Therefore, in this work, wax extraction from sugarcane peel was studied and the influence of different processing parameters evaluated.
\end{abstract}

\section{Key words:}

sugarcane peel, extraction, wax.

\section{Introduction}

Currently, Brazil occupies the position of the world's largest producer of sugarcane and derivatives, being the leading sugar exporter. Harvesting and processing of this quantity of sugarcane generates a lot of waste. In order to promote the best use and valorization of these agroindustrial residues, it is of great interest to transform these materials into substances of higher added value, as the sugarcane wax. Traditionally sugarcane wax has been obtained from rotative filter cake produced during sugar and alcohol production. However, another waste that could be used as wax source is the peel that comes from sugarcane juice production (garapa). Before being sent to juice producers (garapeiros), the stems are scraped to remove their peel. Today, in Brazil, both residues are used as fertilizers in crop fields.

Thus, in this work, wax extraction from sugarcane peel was studied and the influence of different processing parameters evaluated. The influences of particle size, extraction time, amount of solvent, and humidity on the crude wax yield were analysed.

\section{Results and Discussion}

Sugarcane peel was used as raw material. Extractions were performed on a Soxhlet equipment, using nearly 10 $\mathrm{g}$ of biomass (peel). In this work, a standard extraction procedure was considered initially. In this procedure, the following conditions were used: $200 \mathrm{~mL}$ of hexane, 0.26 $\mathrm{mm}$ of particle diameter, and 4 hours of extraction. For the next extractions, only one parameter was modified at each time according to Chart 1 . The extraction time was studied in the range of 1 to 4 hours, solvent amount varied from 200 to $300 \mathrm{~mL}$, particle size from 0.088 to $0.35 \mathrm{~mm}$, and humidity from 7 to $84 \%$.

Chart 1 shows the influence of each parameter on crude wax yield. It is verified that decreasing the particle size, it is possible to increase sugarcane wax yield more than 3 times. Particle's size exerts great influence on extraction process, once reduced particles present higher superficial area, favoring solid-fluid contact. The influence of moisture is very relevant. Once wax is a lipophilic material, the presence of water hinders wax extraction.
Thus, higher moisture content leads to lower crude wax yields.

Considering time and solvent amounts, there were no large quantitative differences among the trials, which is evident by their standard deviation. Probably, the minimum amount of solvent used in this study is enough to extract the wax.

Chart 1. Influence of wax extraction process parameters on crude wax yield

\begin{tabular}{|c|c|c|c|}
\hline Parameter & Value & $\begin{array}{c}\text { Yield } \\
\text { Average }\end{array}$ & $\begin{array}{c}\text { Standard } \\
\text { deviation }\end{array}$ \\
\hline \multirow{3}{*}{ Humidity (\%) } & 7.98 & 6.83 & 0.20 \\
\cline { 2 - 4 } & 61.23 & 2.21 & 0.49 \\
\cline { 2 - 4 } & 83.27 & 0.14 & 0.06 \\
\hline \multirow{3}{*}{$\begin{array}{c}\text { Particle Size } \\
\text { (mm) }\end{array}$} & 0.35 & 2.85 & 0.91 \\
\cline { 2 - 4 } & 0.177 & 7.73 & 0.25 \\
\cline { 2 - 4 } & 0.088 & 9.73 & 0.21 \\
\hline \multirow{2}{*}{$\begin{array}{c}\text { Extraction } \\
\text { time (h) }\end{array}$} & 1 & 5.9 & 0.43 \\
\cline { 2 - 4 } & 2.5 & 6.76 & 0.13 \\
\cline { 2 - 4 } & 4 & 6.65 & 0.21 \\
\hline \multirow{2}{*}{$\begin{array}{c}\text { Amount of } \\
\text { solvent (mL) }\end{array}$} & 200 & 7.22 & 0.05 \\
\cline { 2 - 4 } & 250 & 7.15 & 0.14 \\
\hline
\end{tabular}

\section{Conclusions}

In the analysis of the operating conditions of sugarcane peel wax, the moisture and particle size were the factors that most influenced the yield of crude wax. The amount of solvent and the extraction time, under the conditions studied, practically did not affect yield values.

\section{Acknowledgement}

The authors are grateful for the opportunity and financial support of CNPq / PIBIC-EM, FAEPEX / PRP / UNICAMP (519.292-0307 / 16) and FAPESP (2015 / 25384-1).

CONAB - National Supply Company. Follow-up of the Brazilian Crop of Sugarcane, v. 2 - Safra 2015/16, n.2 - Second survey, Brasília, p. 1-33, 2015.

DOI: 10.19146/pibic-2017-78790 